\title{
Caracterização antigênica e molecular de oito amostras do vírus da doença de Aujeszky isoladas no estado do Rio Grande do Sul em 2003 ${ }^{1}$
}

\author{
Alessandra D’Ávila da Silva ${ }^{2,3}$, Vinícius A. Sortica ${ }^{2,4}$, Alexandre C. Braga ${ }^{2}$, Fernando \\ R. Spilki ${ }^{2,4}$, Ana C. Franco ${ }^{2}$, Paulo A. Esteves ${ }^{2,3}$, Frans Rijsewijk ${ }^{5}$, Júlio César A. \\ Rosa $^{2}$, Helena Beatriz C.R. Batista ${ }^{2}$, Anna P. Oliveira ${ }^{2,4}$ e Paulo M. Roehe ${ }^{2,4^{*}}$
}

\begin{abstract}
D’Ávila da Silva A., Sortica V.A., Braga A.C., Spilki F.R., Franco A.C., Esteves P.A., Rijsewijk F., Rosa J.C.A., Batista H.B.C.R., Oliveira A.P. \& Roehe P.M. 2005. [Antigenic and molecular characterization of eight samples of Aujeszky's disease virus isolated in the state of Rio Grande do Sul, Brazil, in 2003.] Caracterização antigênica e molecular de oito amostras do virus da doença de Aujeszky isoladas no estado do Rio Grande do Sul em 2003. Pesquisa Veterinária Brasileira 25(1):21-24. Instituto de Pesquisas Veterinárias Desidério Finamor (IPVDF), Fepagro Saúde Animal, Estrada do Conde 6000, Cx. Postal 47, Eldorado do Sul, RS 92990-000, Brazil. E-mail: proehe@ufrgs.br

Pseudorabies or Aujeszky's disease (AD), caused by pseudorabies virus (PRV) is a major concern in swine production. In the state of Rio Grande do Sul, Brazil, AD was only detected in 1954, in cattle. In 2003 two outbreaks of encephalitis occurred on the northern region of the state, close to the border with the state of Santa Catarina. Pseudorabies virus (PRV) was isolated from distinct farms within the region and subjected to antigenic and genomic analyses. These isolates were compared with prototype strains NIA-3 and NP. Antigenic characterization with a panel of monoclonal antibodies (Mabs) directed to viral glycoproteins (gB, gC, $\mathrm{gD}$ and $\mathrm{gE}$;) was performed by an imunoperoxidase monolayer assay (IPMA) on infected cell monolayers. Genomic characterization was carried out by restriction enzyme analysis (REA) of the whole DNA viral genome with Bam $\mathrm{HI}$. The antigenic profile of the eight isolates from Rio Grande do Sul as well as strains NIA-3 and NP were similar. REA analysis revealed that all isolates from Rio Grande do Sul displayed a genomic type II arrangement, a genotype often found in other outbreaks of $\mathrm{AD}$ previously reported in other Brazilian states. The results obtained suggest that the eight isolates examined here were similar.
\end{abstract}

INDEX TERMS: Aujeszky's disease, epidemiology.

RESUMO.- A doença de Aujeszky ou pseudoraiva (DA), causada pelo vírus da pseudoraiva (PRV) é a maior preocupação na produção de suínos. No estado do Rio Grande do Sul, Brasil, a

\footnotetext{
${ }^{1}$ Recebido em 12 de agosto de 2004.

Aceito para publicação em 27 de dezembro de 2004.

${ }^{2}$ Instituto de Pesquisas Veterinárias Desidério Finamor (IPVDF), Fepagro Saúde Animal, Estrada do Conde 6000, Cx. Postal 47, Eldorado do Sul, RS 92990-000, Brasil.

${ }^{3}$ Programa de Pós-Graduação em Ciências Veterinárias, Faculdade de Veterinária, Universidade Federal do Rio Grande do Sul (UFRGS), Av. Bento Gonçalves 9090, Porto Alegre, RS 91540-000, Brasil.

${ }^{4}$ Departamento de Microbiologia, Laboratório de Virologia, Universidade Federal do Rio Grande do Sul (UFRGS), Porto Alegre, RS 90050-170, Brasil. "Autor para correspondência: Cx. Postal 2076, Porto Alegre, RS 90001-970. E-mail: proehe@ufrgs.br

${ }^{5}$ Animal Sciences Group, P.O. Box 65, 8200 AB Lelystad, Paises Baixos.
}

DA foi somente detectada em 1954, em bovino. Em 2003, ocorreram dois surtos de encefalite em granjas na região norte do estado, fronteira com o estado de Santa Catarina. O vírus da doença de Aujeszky (VDA) foi isolado a partir de animais coletados em oito granjas distintas da região e submetido a análises antigênicas e moleculares. As amostras de VDA isoladas foram comparadas com as amostras padrão NIA-3 e NP. A caracterização antigênica dos mesmos foi realizada com testes de imunoperoxidase frente a um painel de anticorpos monoclonais (Mabs) preparado contra epitopos de glicoproteinas virais ( $\mathrm{gB}, \mathrm{gC}, \mathrm{gD}$ e gE). A caracterização genômica foi realizada através da análise restrição enzimática (REA) sobre o genoma total das amostras, com a enzima de restrição (REA) Bam HI. O perfil antigênico das oito amostras isoladas no Rio Grande do Sul, bem como os apresentados pelas amostras padrão NIA-3 e $\mathrm{NP}$, foram similares. A REA revelou que todos as oito amostras 
do Rio Grande do Sul apresentaram um arranjo genômico do tipo II, genótipo frequentemente encontrado em surtos prévios de DA em outros estados do Brasil. Os resultados aqui obtidos indicam que as oito amostras isoladas no Rio Grande do Sul são similares.

TERMOS DE INDEXAÇÃO: Doença de Aujesky, epidemiologia.

\section{INTRODUÇÃO}

O vírus da Doença de Aujeszky (VDA) pertence à família Herpesviridae, subfamília Alphaherpesvirinae, gênero Varicellovirus (Murphy et al. 1999). O VDA possui um genoma de DNA de fita dupla com aproximadamente 150 pares de base (Kpb), que codifica mais de 70 proteínas (Mettenleiter 1991). Também conhecida como Pseudoraiva, a Doença de Aujeszky é considerada uma importante causa de perdas econômicas em rebanhos de suínos, estando difundida em todo o mundo, inclusive no Brasil (Cândido et al. 2000, Piatti et al. 2001).

O VDA compartilha características comuns a outros membros da família Herpesviridae. Após a infecção primária, o vírus migra para gânglios nervosos, via terminações nervosas periféricas, podendo estabelecer infecção latente ou invadir o Sistema Nervoso Central (SNC). 0 estabelecimento de latência torna o animal uma fonte de disseminação viral durante toda a vida. $O$ vírus pode reativar da latência e ser excretado quando o animal sofre algum estresse (Murphy et al. 1999, Sobestiansky et al. 1999).

Os suínos são os principais reservatórios do VDA, sendo a principal fonte de infecção para os hospedeiros secundários, que incluem eqüinos, bovinos, ovinos, caprinos, caninos e felinos (Murphy et al. 1999). Em leitões não imunes, a enfermidade caracteriza-se por sinais de comprometimento neurológico e respiratório. Assim, as perdas relacionadas à DA são decorrentes das altas taxas de mortalidade e morbidade de leitões, queda da produtividade de reprodutores e redução do desenvolvimento dos animais em crescimento e terminação (Sobestiansky et al. 1999).

Em função das infecções latentes, o vírus pode periodicamente ser re-excretado pelos animais infectados, podendo disseminar a infecção no rebanho. Animais portadores da infecção latente são potenciais fontes de infecção durante toda a vida (Sobestiansky et al. 1999).

No Estado do Rio Grande do Sul (RS), o VDA foi detectado pela primeira vez em um bovino no ano de 1954 (Bauer 1954, 1954/1955). Desde então, a presença do vírus ou evidências sorológicas indicando endemicidade não foram mais encontradas no Estado. Estudos sorológicos realizados posteriormente não detectaram a presença de anticorpos para a enfermidade, tanto em granjas comerciais de suínos domésticos (Oliveira et al. 1987, Trevisol et al. 1995, Roehe et al. 1996) como de javalis (Braga et al. 2002). Passado meio século do primeiro (e único) registro da DA no RS, dois surtos ocorreram em plantéis de suínos domésticos em granjas localizadas no norte do Estado, no ano de 2003 (Groff et al. 2005).

Este artigo relata a caracterização antigênica e molecular de oito amostras do VDA isoladas nos dois surtos ocorridos no ano de 2003 no RS.

\section{MATERIAL E MÉTODOS}

\section{Vírus e células}

Oito amostras de vírus foram isoladas de órgãos de suínos que apresentavam sintomatologia clínica compatível com DA. Os animais eram provenientes de granjas distintas, com suspeita de ocorrência da enfermidade (Quadro 1). O diagnóstico foi realizado através do isolamento viral em cultivos celulares e posterior confirmação da identidade do vírus por imunoperoxidase utilizando anticorpos específicos. Como controles, foram utilizadas as amostras NP (Bauer 1954/1955) e a amostra NIA-3 (Brittle et al. 2004). As oito amostras isoladas dos dois surtos foram denominadas "EVI 011/03, EVI 149/03, EVI 151/03, EVI 174/03, EVI 176/03, EVI 177/03, EVI 192/03 e EVI 193/03" (Quadro 1). As amostras de vírus foram isoladas e multiplicadas em células de linhagem de rim suíno "SK6" e de rim bovino MDBK, rotineiramente mantidas em Meio Essencial Mínimo (MEM) contendo enrofloxacina $(50 \mathrm{mg} / \mathrm{L})$ e $10 \%$ de soro fetal bovino (Nutricell).

Quadro 1. Amostras de vírus da doença de Aujeszky examinadas no presente estudo e municípios de origem das mesmas. Todas as amostras foram isoladas dos dois surtos ocorridos no Rio Grande do Sul em 2003

\begin{tabular}{cl}
\hline $\begin{array}{c}\text { Amostras } \\
\text { de vírus }\end{array}$ & \multicolumn{1}{c}{$\begin{array}{c}\text { Local de origem/ } \\
\text { referência }\end{array}$} \\
\hline EVI $011 / 03$ & Pinheirinho do Vale/RS \\
EVI $149 / 03$ & Aratiba/RS \\
EVI $151 / 03$ & Aratiba/RS \\
EVI $174 / 03$ & Aratiba/RS \\
EVI $176 / 03$ & Aratiba/RS \\
EVI $177 / 03$ & Erechim/RS \\
EVI $192 / 03$ & Erechim, Ponte Preta/RS \\
EVI $193 / 03$ & Erechim/RS \\
NPa & Guaporé (Bauer1954/55) \\
NIA-3 & \\
\hline a Controles. &
\end{tabular}

\section{Análise com endonuclease de restrição}

O DNA viral das amostras foi extraído como descrito previamente (Franco et al. (2002). A análise com endonuclease de restrição (REA) foi realizada como descrito por Sambrook et al. (2001) com a enzima Bam HI. Os fragmentos foram separados em gel de agarose a $0,5 \%$ a $10 \mathrm{~V}$, corados com brometo de etídio e visualizados em um transiluminador com luz ultravioleta (UV) seguindo métodos usuais (Sambrook et al. 2001). As amostras foram classificadas de acordo com os perfís de arranjo genômico conforme Herrmann et al. (1984).

\section{Determinação do perfil antigênico por imunoperoxidase}

Os sobrenadantes dos cultivos infectados foram inoculados em monocamadas pré-formadas em placas de cultivo celular de 96 orifícios. Quando o efeito citopático (ECP) foi evidenciado em cerca de 10-20\% das células infectadas, as culturas foram fixadas com paraformaldeído a $4 \%$ em PBS (pH 7.2). O teste de imunoperoxidase em monocamada (IPMA) foi realizado como descrito por Kramps et al. (1996). Como anticorpo primário foram utilizados anticorpos monoclonais (Acms) dirigidos contra as glicoproteínas virais $\mathrm{gB}, \mathrm{gC}$, $\mathrm{gD}$ e gE. Como anticorpo secundário foi utilizado um conjugado anti-IgG de camundongo/ peroxidase (Dakoâ).

\section{RESULTADOS}

\section{Análise com endonuclease de restrição (REA)}

Uma foto representativa dos resultados obtidos à REA é mostrado na Figura 1. A determinação do arranjo genômico é base- 
a)

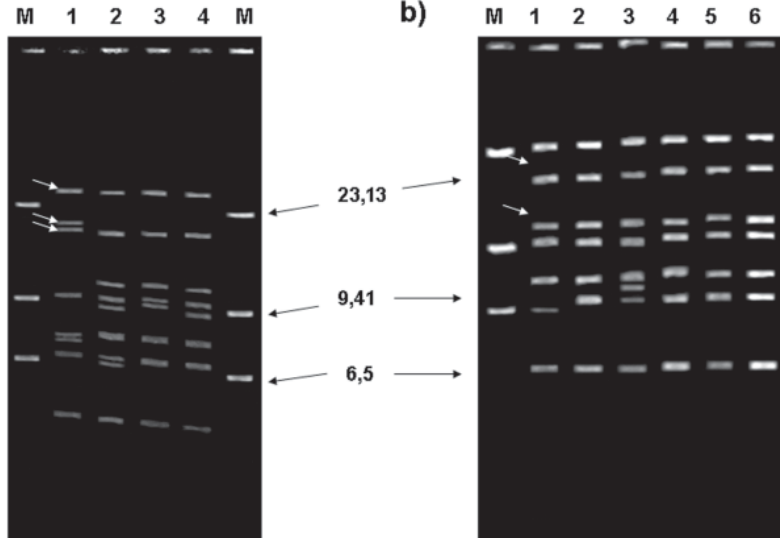

Fig.1. Foto representativa do resultado das análises de restrição enzimática (REA) com a enzima Bam HI sobre amostras do vírus da doença de Aujeszky: a) M: marcador de tamanho de DNA (ë Hind III); linha 1: amostra controle NIA-3 (tipo 1); linha 2: amostra controle NP (tipo 2); linhas 3 e 4: isolados do Rio Grande do Sul EVI 192/03 (linha 3) e EVI 193/03 (linha 4). b) M: marcador; linha 1: EVI 149/03; linha 2: EVI 151/03; linha 3: EVI 011/03; linha 4: EVI 174/ 03; linha 5: EVI 176/03; linha 6: EVI 177/03. Setas pretas: tamanhos dos fragmentos de DNA de referência. Setas brancas: segmentos considerados para a tipagem. Números entre as figuras referem-se ao tamanho (em kilopares de bases; kbp) dos segmentos do marcador de DNA.

ada no posicionamento dos três segmentos maiores obtidos após a restrição enzimática com Bam $\mathrm{HI}$ (Herrmann et al. 1984), não sendo consideradas as variações nos segmentos menores, em função de sua grande variabilidade. Segundo esse critério, as oito amostras isoladas no RS apresentaram um arranjo genômico denominado tipo II, sem apresentar diferenças consideradas significativas no tamanho dos mesmos.

\section{Análise antigênica}

As oito amostras isoladas dos dois surtos da doença no RS apresentaram o mesmo perfil de reatividade antigênica frente aos Acms utilizados (Quadro 2). Igualmente, não houve diferenças entre os perfis apresentados pelas amostras isoladas e aque-

Quadro 2. Perfil de reatividade de anticorpos monoclonais anti-glicoproteínas do vírus da doença de Aujeszky (VDA) em testes de imunoperoxidase sobre monocamadas de células MDBK

\begin{tabular}{ccccc}
\hline Amostras & \multicolumn{4}{c}{ Anticorpos monoclonais } \\
\cline { 2 - 5 } de vírus & anti-gB & anti-gC & anti-gD & anti-gE \\
\hline EVI 011/03 & + & + & + & + \\
EVI 149/03 & + & + & + & + \\
EVI 151/03 & + & + & + & + \\
EVI 174/03 & + & + & + & + \\
EVI 176/03 & + & + & + & + \\
EVI 177/03 & + & + & + & + \\
EVI 192/03 & + & + & + & + \\
EVI 193/03 & + & + & + & + \\
NPa + & + & + & + & \\
NIA-3 & + & + & + & +
\end{tabular}

aAmostras utilizadas como controles. les apresentados pelas amostras tomadas como padrões (NIA-3 e NP).

\section{DISCUSSÃO}

Até a ocorrência do surto objeto do presente estudo, a doença de Aujeszky era tida como uma enfermidade exótica ao Estado do RS. O único caso anteriormente registrado da enfermidade no Estado ocorreu em 1954, no município de Guaporé, onde somente um animal da espécie bovina foi afetado (Bauer 1954, 1954/1955). Esta situação epidemiológica justifica a necessidade de um aprofundamento no estudo das caraterísticas das amostras isoladas no episódio de 2003. Após a confirmação do diagnóstico, o primeiro aspecto a ser analisado foi a verificação de possíveis variações entre as diferentes amostras isoladas do surto. Tanto a REA como a análise com Acms indicaram não haver diferenças entre as amostras isoladas do surto. Quanto ao perfil genotípico, os isolados apresentaram um arranjo genômico do tipo II, segundo classificação previamente proposta (Herrmann et al. 1984) e adotada por diversos outros autores (Yamada et al. 1992, Banks 1993, Capua et al. 1997, Piatti et al. 2001). Segundo a classificação proposta por aqueles autores, os arranjos genômicos são diferenciados pelo padrão obtido à clivagem dos três fragmentos maiores originários da REA. O genotipo I tem sido encontrado nos Estados Unidos da América e Europa Central; o genotipo II tem sido descrito na Europa Central e no Japão; já o tipo III tem sido detectado apenas no norte da Europa (Herrmann et al. 1984). O genotipo II, que caracterizou as amostras isoladas no presente trabalho, é o genotipo mais frequentemente detectado no Brasil. Em estudo prévio, este foi o único genotipo detectado em 19/19 amostras examinadas provenientes do Estado de Santa Catarina. Em estudo prévio, 28 de 30 amostras isoladas nos estados de Santa Catarina, Paraná e São Paulo apresentavam genotipo II (Piatti et al. 2001).

A DA no Brasil tem sido registrada nos Estados de Santa Catarina, Paraná, Minas Gerais e São Paulo. Nestes, o controle da doença é realizado através de inquéritos sorológicos e eliminação de animais soropositivos, sendo autorizada a vacinação em certas circunstâncias (Mores \& Zanella 2003). Entretanto, a ocorrência de DA em Santa Catarina e a inexistência da mesma no RS, estados cuja fronteira é delimitada pelo rio Uruguai em sua maior parte, têm preocupado a todos os envolvidos na vigilância sanitária da região. A proximidade entre os estados aumenta a possibilidade da circulação do vírus. Contudo, ao longo de quarenta e nove anos não foi detectada a presença deste vírus no estado do RS, provavelmente em função do fluxo do comércio desses animais, que tende a levar animais do RS em direção ao norte, e não no sentido inverso (Oliveira et al. 1987, Trevisol et al. 1995, Roehe et al. 1996, Braga et al. 2002). Muito provavelmente, questões econômicas, tal como a queda de preço de leitões em determinado momento no Estado de Santa Catarina, parecem ter influenciado a mudança deste fluxo, o que provavelmente foi o fator determinante do surto objeto desse estudo.

Uma vez detectado o surto, tornou-se imperativo caracterizar as amostras circulantes, com o objetivo de determinar prováveis fontes de infecção. A proximidade da região de ocorrência dos focos com a fronteira com o Estado de Santa Catarina, 
associada ao perfil genômico e antigênico identificado nas amostras permitem concluir que a provável origem do surto foi o Estado vizinho.

As análises aqui realizadas foram importantes para o rastreamento epidemiológico da origem do surto. Além disso, os resultados obtidos foram importantes para que a vigilância epidemiológica na região fosse reforçada. Desde o episódio aqui descrito, não foram mais detectados surtos da enfermidade no Estado do Rio Grande do Sul.

Agradecimentos.- Os autores agradecem ao CNPq, à CAPES e FAPERGS pelo suporte financeiro. A.D. Silva e P.A. Esteves são alunos do Programa de Pós Graduação em Ciências Veterinárias, Faculdade de Veterinária da Universidade Federal do Rio Grande do Sul, bolsistas CAPES. P.M. Roehe é pesquisador bolsista do CNPq.

\section{REFERÊNCIAS}

Banks M. 1993. DNA restriction fragment length polymorphism among British isolates of Aujeszky's disease virus: use of the polymerase chain reaction to discriminate among strains. Brit. Vet. J.149:155-163.

Bauer A.G. 1954. Mal de Aujeszky. Bolm Dir. Prod. Anim., Porto Alegre, 20:25. Bauer A.G. 1954/1955. Primeira constatação do mal de Aujeszky no Rio Grande do Sul. Bolm Inst. Pesq. Vet. Desidério Finamor. 1:15-16.

Braga A.C., Martin M.S., Oliveira S. J., Rosa J.C.A., Schmidt E.\& Martin C.R. 2002. Avaliação sorológica para a doença de Aujeszky em granjas comerciais de javalis (Sus scrofa scrofa) no Rio Grande do Sul. Anais XXIX Congr. Bras. Med. Veterinária, 10-14 out., Gramado, RS. 1 CD-ROM.

Cândido A.L., Resende M., Oliveira M.E., Bontempo E.D. \& Drumond B.P. 2000. Partial characterization of a Brazilian strain of Aujeszky's disease virus recovered from a pig with subclinical infection. Arq. Bras. Med. Vet. Zootec. 52(4):295-301.

Capua I., Casaccia C., Calzeta G. \& Caporale V. 1997. Characterization of Aujeszky's disease viruses isolated from domestic animals and from a wild boar (Sus scrofa) in Italy between 1972 and 1995. Vet. Microbiol. 51:143-149.

Brittle E.E., Reynolds A.E. \& Enquist L.W. 2004. Two modes of pseudorabies virus neuroinvasion and lethality in mice. J. Virol. 78 (23):12951-63.

Franco A.C., Rijsewijk, F.A.M., Flores E.F., Weiblen R. \& Roehe P.M. 2002. Construction and characterization of a glycoprotein E deletion mutant of bovine herpesvirus type 1.2 strain isolated in Brazil. Braz J. Microbiol. 33(3):274-278.
Groff F.H.S., Merlo M.A., Stoll P.A., Stepan A.L., Weiblen R. \& Flores E.F. 2005. Epidemiologia e controle dos focos de Doença de Aujeszky no Rio Grande do Sul, em 2003. Pesq Vet. Bras. 25(1):25-30.

Herrmann S.C., Heppner B. \& Ludwig, H. 1984. Pseudorabies viruses from clinical outbreaks and latent infections grouped into four major genome types. In: Wittmann G., Gaskell R.M. \& Rziha H.J. (ed.) Latent Herpesvirus Infections in Veterinary Medicine. Curr. Top. Vet. Med. Anim. Sci. 27:378401.

Kramps J.A., Perrin B., Edwards S. \& van Oirschot J.T. 1996. An European inter-laboratory trial to evaluate the reliability of serological diagnosis of bovine herpesvirus 1 infections. Vet. Microbiol. 53:153-161.

Mettenleiter TC. 1991. Molecular biology of pseudorabies (Aujeszky's disease) virus. Comp. Immunol. Microbiol. Infect. Dis. 14(2):151-63.

Morés N. \& Zanella J.C. 2003. Programa de erradicação da doença de Aujeszky no Estado de Santa Catarina. Anais XI Congr. Vet. Esp. Suínos, 30 set. - 3 out., Goiânia, Goiás, p.126-131.

Murphy F.A., Gibbs, E.P., Horzinek, M.C. \& Studdert M.J. 1999. Veterinary Virology. 3rd ed. Academic Press, New York. 629 p.

Oliveira S. J., Guizzardi I.I., Vedar T., Oliveira L.G., Bruchmann H.E.A., Martins R.M., Roehe P.M. \& Bangel E.V. 1987. Testes sorológicos para o diagnóstico de leptospirose, peste suína africana e doença de Aujeszky em granjas de reprodutores suínos no Rio Grande do Sul, ano 1984. Arq. Bras. Med. Vet. Zootec. 39(3):451-460.

Piatti R.M., Ikuno A.A., Cunha E.S., D’Ambros R., Gregori F., Soares R.M., Cortez A. \& Richtzenhain L.J. 2001. Characterization of Aujeszky's disease virus isolates from south and southeast Brazil by RFLP analysis. Braz. J. Microbiol 32 (2): 144-146.

Roehe P.M., Souza R., SalvoE.O., Martins R.M., Oliveira L.G., Hoffmann V.L., Rosa J.C.A. \& Trevisol, I.M. 1996. Ausência de anticorpos contra o vírus da doença de Aujeszky em suínos no Estado do Rio Grande do Sul. Arq. Bras. Med. Vet. Zootec. 48(3):393-367.

Sambrook J., Fritsch E. \& Maniatis T. 2001. Molecular cloning: A Laboratory Manual. 3rd ed. Cold Spring Harbor Laboratory Press, New York.

Sobestiansky J., Barcellos D.E.S.N., Mores N., Oliveira S.J., Carvalho L.F.O.S., Moreno A.M. \& Roehe P.M. 1999. Clínica e Patologia Suína. $2^{\underline{a}}$ ed. Goiânia, Goiás. 463p.

Trevisol I.M., Oliveira L.G. \& Roehe P.M. 1995. Ausência de anticorpos contra o vírus da doença de Aujeszky em suínos no Estado do Rio Grande do Sul. Anais Congr. Bras. Vet. Esp. Suínos, 7-11 nov., Blumenau, Santa Catarina, p.99.

Yamada S., Nishimori T. \& Shimizu M. 1992. Characterization of pseudorabies viruses recently isolated in Japan by restriction endonuclease assay. Japn J. Vet. Med. Sci. 54:541-549. 